\title{
UM CINECLUBE NO INTERIOR DA AMAZÔNIA: O USO DO AUDIOVISUAL COMO PRÁTICA DE APRENDIZAGEM HISTÓRICA
}

\author{
A MOVIECLUB IN THE INTERIOR OF THE AMAZON: \\ THE USE OF AUDIOVISUAL AS A PRACTICE OF HISTORICAL LEARNING
}

Érico Silva Muniz ${ }^{1}$

Silvane da Silva e Silva²

\begin{abstract}
RESUMO: O presente artigo relata a experiência do Cineclube da Aldeia, uma atividade de extensão universitária na interface entre cinema, ensino de história e formação no campo dos direitos humanos. Realizado na cidade de Bragança, localizada no nordeste paraense, o cineclube promove exibição de filmes que trabalham no âmbito das discussões sobre historiografia, diversidade e formação cidadã seguida de debate sobre o ensino de história. Criado no ano de 2017 a experiência de um cineclube como contribuição metodológica para o ensino de História na Amazônia colabora com o uso crítico do audiovisual nas escolas da educação básica do interior e das periferias mais distantes dos grandes centros urbanos promovendo a aprendizagem histórica.
\end{abstract}

Palavras-chave: Cinema. História. Bragança (PA). Cineclube.

\begin{abstract}
This article reports on the experience of the Village Film Festival, an activity of university extension in the interface between cinema, history teaching and training in the field of human rights. Held in the city of Bragança, located in northeastern Pará, the film festival promotes the exhibition of films that work in the scope of discussions on historiography, diversity and citizen education followed by a debate on the teaching of history. Created in the year 2017, the experience of a film club as a methodological contribution to the teaching of History in the Amazon contributes to a citizen's formation and to the critical use of audiovisual in schools of basic education in the interior and in the more distant peripheries promoting historical learning.
\end{abstract}

Key-words: Cinema. History. Bragança(PA). Movieclub.

1 Doutor em História pela Casa de Oswaldo Cruz/Fundação Oswaldo Cruz. Professor Adjunto da Faculdade de História e do Programa de Pós-Graduação em Linguagens e Saberes na Amazônia. Campus Universitário de Bragança/Universidade Federal do Pará (UFPA).

2 Mestranda no Programa de Pós-Graduação em Diversidade Sociocultural/Museu Paraense Emílio Goeldi.Graduada em História pelo Campus Universitário de Bragança/ Universidade Federal do Pará (UFPA). 


\section{Introdução}

O presente artigo relata a experiência de um cineclube criado como projeto de extensão com a finalidade de discutir o uso do audiovisual no ensino de História fora dos grandes centros urbanos. Iniciado em junho de 2017 , o projeto "O Cineclube da Aldeia e o Ensino de História" é realizado no âmbito da Faculdade de História do Campus Universitário de Bragança da Universidade Federal do Pará (UFPA). Inicialmente a atividade foi pensada como exercício de projeção de filmes e debates sobre Direitos Humanos e historiografia. Pensado como evento aberto à comunidade acadêmica, aos estudantes do ensino médio da rede pública estadual e à sociedade em geral, o projeto tinha ainda por finalidade assegurar a participação de representantes dos diversos movimentos sociais, promovendo encontros entre a universidade e os grupos organizados na cidade.

Bragança é uma cidade no interior da Amazônia que fica situada às margens do Rio Caeté, seu passado remonta à história da ocupação e da colonização da região compreendida entre São Luís e Belém, empreendida em meio às disputas entre a coroa portuguesa, expedições de franceses, holandeses e ingleses na região com marcante presença indígena (SILVA, 2006). A fundação precoce da cidade de Bragança a coloca como uma das mais antigas do estado do Pará. Segundo dados do Instituto Brasileiro de Geografia e Estatística (IBGE), atualmente sua população é estimada em 126.436 habitantes. O município possui 164 escolas de ensino fundamental e 21 escolas de ensino médio, além de contar com 23.749 matrículas de alunos do ensino fundamental e 5.845 alunos no ensino médio. Em 2015 eram 1.050 docentes atuando no ensino fundamental e 395 no ensino médio ${ }^{3}$.

Vários são os indicadores das desigualdades sociais existentes na cidade. Com Índice de Desenvolvimento Humano (IDH) de 0,60, a cidade registrava no ano de 2010 a $4144^{a}$ posição entre os 5.565 municípios brasileiros ${ }^{4}$. Além disso, a instalação de um centro do ProPaz Integrado em 2012, um programa da Secretaria de Segurança Pública e Defesa Social do estado do Pará que busca atender crianças, adolescentes, mulheres e suas famílias em situação de violência; e uma

3 Dados compilados pelo site IBGE Cidades (IBGE, 2017).

4 Informações do Atlas do Desenvolvimento Humano do Brasil (2018). 
Delegacia Especializada de Atendimento à Mulher (DEAM) têm visibilizado opressões específicas, notadamente as expressões do machismo e de crimes de feminicídio na sociedade bragantina ${ }^{5}$.

Esta cidade recebeu um campus da UFPA no ano de 1987. Com um processo de interiorização da universidade para um maior número de localidades na Amazônia vivido à época, Bragança foi escolhida para a implementação de um campus universitário. "Em 1992 foram ofertados na modalidade regular, os cursos de Licenciatura Plena em Letras com habilitação em Língua Portuguesa, Pedagogia e Matemática. Nesse período ingressam os primeiros docentes para assumirem os cursos implantados" (UFPA, 2018). Atualmente o campus conta com 8 cursos de graduação, quase todos na modalidade de licenciatura. Na rede pública, as unidades escolares mais próximas ao campus, são as escolas Yolanda Chaves e Prof. Bolívar Bordalo da Silva. Ambas instituições que frequentemente colaboram com projetos de pesquisa e extensão da universidade, além da aproximação propiciada pela realização dos estágios supervisionados obrigatórios por parte dos discentes do campus.

O uso do cinema nas salas de aula dessas escolas em Bragança e na região amazônica não é de todo uma novidade na agenda dos docentes da educação básica. Podendo ser entendido como técnica, instrumento formador de cidadania, de agentes históricos e até mesmo de historicidade, o cinema surgiu no século XIX como necessidade de registro em movimento, em meio ao processo de modernidade europeia abrindo caminho para estudos relacionados à relação entre cinema e história (FERRO, 1992).

Atualmente, devido ao avanço da tecnologia de informação a utilização de filmes tornou-se uma metodologia bastante difundida entre os professores da educação básica. É importante ressaltar que os métodos lúdicos ou qualquer outro método por si só não produzem uma participação dos alunos, assim como não conduzem a uma formação crítica, cabendo ao professor um papel destacado na mediação desse processo de ensino-aprendizagem. Desse modo, o projeto "O Cineclube da Aldeia e o Ensino de História" estruturou-se pela necessidade observada no cotidiano escolar da conscientização para os problemas sociais da

5Sobre o ProPaz Integrado, os dados obtidos são da Secretaria de Segurança Pública e Defesa Social do estado do Pará (MOREIRA, 2018). 
cidade através da extensão universitária com a potencialidade educativa da sétima arte.

O cinema, aliás, articula-se frequentemente com a produção de novas visões de mundo, possibilitando ao professor a sua utilização para promover debates sobre os mais diversos temas, entre assuntos de ordem social, debates acadêmicos ou historiográficos. A proposta da atividade foi promover uma reflexão sobre temas relacionados aos direitos humanos que se revelassem enquanto problemas sociais para a realidade local. Notadamente, temas relativos a diversidade sexual, questões étnico-raciais, saberes tradicionais e feminismos. Dessa forma, nos aproximamos dos debates de Jörn Rüsen (2010) sobre a necessidade de empreendermos uma aprendizagem histórica buscando apresentar o fazer histórico como processo de compreensão da realidade local no tempo presente através de obras de cunho artístico e ficcional.

Tal opção justificou-se pelo cenário local em consonância com os dilemas do Brasil contemporâneo, onde os diagnósticos sobre a educação mostram que a mesma não cumpre uma função emancipatória e de formação cidadã. Ao contrário observa-se o crescimento de comportamentos racistas, misóginos, LGBTfóbicos, discriminatórios contra populações indígenas entre outros discursos de ódio que são levantados em relação às chamadas classes subalternas.

Esses segmentos sociais historicamente considerados não hegemônicos passaram por diversos enquadramentos históricos. Chalhoub (1996) cunhou em sua obra "Cidade Febril" a categoria "classes perigosas", que são aqueles grupos sociais formados à margem da sociedade na história do Brasil republicano. Essa categoria polissêmica serviu para designar aqueles considerados à margem da lei. No Brasil encontramos o conceito de "classes perigosas" como um eixo principal no debate parlamentar da Câmara dos deputados do Império em maio de 1888, período da lei da abolição da escravatura. Os deputados preocupados com isso e no combate à ociosidade, utilizaram como fonte as definições de alguns autores franceses, especialmente o trabalho de M. A. Frégier (1789-1860), um funcionário da polícia que baseado nas estatísticas policiais e inquéritos escreveu sobre as "classes perigosas da população das grandes cidades", fazendo alusão a ideais eugenistas e preocupando-se em descrever detalhadamente os "malfeitores" que tomavam contas das ruas de Paris (CHALHOUB, 1996, p. 21). Seu estudo acabou 
por ampliar a descrição das condições de vida dos pobres parisienses, além de falhar em gerar qualquer fronteira entre as "classes perigosas" e as "classes pobres".

Ainda que com distintos enquadramentos, as classes perigosas ou subalternas seguem sendo criminalizadas no Brasil do tempo presente. A comunidade LGBT (Lésbicas, gays, bissexuais, travestis, transexuais e intersexos), por exemplo, vivencia amplamente essa discriminação. Dados levantados pelo Grupo Gay da Baia (GGB) dão conta que apenas em 2017 foram 445 os crimes com morte envolvendo a comunidade LGBT (MOTT; MICHELS; PAULINHO, [2018]). Segundo o jornal O Globo, esse aumento foi de 30\% em relação a 2016. Em geral esses crimes ficam sem punição, menos de $10 \%$ das ocorrências resultaram em abertura de processo e punição dos assassinos. A realidade parece ser ainda pior, pois especialistas ponderam que a maior parte das agressões e expressões da violência psicológica contra as pessoas LGBTs permanecem na subnotificação (SOUTO, 2018).

As estatísticas sobre preconceito contra a população negra no Brasil são também bastante emblemáticas. Segundo o Atlas da Violência 2018, produzido pelo Instituto de Pesquisa Econômica Aplicada (IPEA) e pelo Fórum Brasileiro de Segurança Pública (FBSP), a violência contra os negros mostra o tamanho da desigualdade étnica no Brasil. Em 2016 a taxa de homicídio da população negra foi duas vezes e meia superior à taxa de homicídios de não negros. A situação se agrava quando cruzada com a condição de gênero, sendo a taxa de feminicídio de mulheres negras 71\% superior à de mulheres não negras (IPEA; FBSP, 2018).

É nesse mesmo cenário que se situa a misoginia e a violência contra as mulheres. Ainda de acordo com dados do FBSP no ano de 2016 um total de 193.000 mulheres registraram queixa por violência doméstica no país. Além dos casos de feminicídio, as mulheres são vítimas de diversos crimes como constrangimento ilegal, calúnia e difamação, sedução e injúria. De acordo com a Folha de São Paulo, o Brasil registrou 164 casos de estupros por dia no ano de 2017. A subnotificação desses crimes convive com outras modalidades de opressão, tais como assédio no espaço de trabalho, em via pública e em outros lugares (AMÂNCIO, 2018). 
A identificação desse cenário brasileiro que se aplica de maneira muito semelhante às mazelas sociais dos habitantes da Amazônia motivou a estruturação de um cineclube como ação educativa, buscando demandas de grupos sociais que historicamente não detiveram o poder para impô-las. Nesse sentido, a busca pela aprendizagem histórica através de um cineclube articula-se com elementos teóricos e metodológicos de pesquisa sobre cinema e história, mas também está pautada pelas demandas sociais do tempo presente (RÜSEN, 2010). A seguir analisaremos os acúmulos e os limites que essa experiência tem promovido na cidade de Bragança (PA), atentando aos seus ganhos e possibilidades de implementação na educação básica.

Para compreender essa experiência e apresentar as dinâmicas do uso do audiovisual como ferramenta metodológica na escola, descreveremos a seguir as etapas de realização do Cineclube da Aldeia, antes disso, faz-se necessário debater no âmbito da História e da Educação o uso do cinema na pesquisa e na sala de aula.

\section{O audiovisual como método}

Os processos de produção de filmes e as influências políticas e sociais que eles possuem saíram do obscurantismo acadêmico especialmente a partir dos trabalhos do historiador Marc Ferro. O autor postulou na década de 1980 que o cinema aparece primeiramente como um agente da história, que inicialmente surgiu como um instrumento da modernidade. Com o acúmulo de trabalhos que hoje ultrapassam o pensamento de Ferro sabemos que historicamente o cinema é usado para enfatizar ideologias, sobre as quais os cineastas possuem graus variados de consciência, ou seja, um filme que tem por missão retratar uma determinada sociedade e a sua cultura será sempre um desafio, pois a intervenção do Cinema acontece a partir de um certo "modo de ação", que torna o filme eficaz. Existem diferentes graus de interação entre a sociedade que produz o filme e a que o recebe (FERRO, 1992; MORETTIN, 2003).

Para Novóa (2008), a relação cinema-história funciona como um objeto de investigação e ao mesmo tempo uma problemática que interroga a investigação. Para o autor, o cinema no século $X X$ teve maior impacto na sociedade que outras 
expressões sociológicas, historiográficas ou pedagógicas. Nessa perspectiva, as obras de arte são "filhas de seu tempo" repassam os valores, cultura e a consciência social e histórica do tempo em que foram produzidas, ou seja, podemos entender que da mesma forma a relação cinema-história problematiza o seu mundo, o seu tempo e seus fenômenos. Além disso, o cinema possui um grande poder de comunicação justamente devido a aspectos inerentes aos seres humanos, quando a razão se mistura permanentemente com os pensamentos e sentimentos. Segundo Novóa (2008), podemos perceber essa dimensão sensorial de maneira particular quando estamos assistindo algo e aparecem cenas de dor, alegria ou raiva e, de uma certa forma, nos vemos tensionados a compartilhar do sentimento que está sendo expressado.

Pensar o cinema com base na história social é uma abordagem que vem crescendo ao longo dos anos, segundo Valim (2005), no Brasil apesar de existirem estudos nessa área a partir de 1990, no entanto, não há ainda no país uma historiografia consolidada que aborde de maneira frequente o cinema do ponto de vista da história social. Valim analisa alguns trabalhos de autores que mencionam a relação cinema-história como Marc Ferro, Michele Lagny, Pierre Sorlin, Ciro Flamarion Cardoso, Barbara Klinger entre outros, e discute o Cinema também na perspectiva de um agente da história. Segundo os argumentos de Michele Lagny ele não é apenas uma prática social, mas também um gerador de práticas sociais. Pode-se entender que assim como o cinema pode ser um testemunho da forma de pensar, agir e sentir de uma determinada sociedade, ele também pode ser um agente que suscita certas transformações, veicula representações e apresenta modelos. Seguindo Sorlin, podemos ainda investigar os meios que alguns filmes utilizam para induzir o público a se identificarem com as suas ideologias, as posições e as representações sociais e políticas dominantes e as resistências a essas mensagens dominantes que podem gerar novas leituras à apropriação do cinema (SORLIN, 1985 apud VALIM, 2005).

A interpretação de filmes deve levar em conta, portanto, o contexto de produção, para se verificar como se relaciona com as estruturas dominantes e com as forças de resistência. Deve-se evitar o erro de querer ler um filme como uma sociedade inteira, deve-se tratá-lo como um conjunto de representações que retratam direta e indiretamente o período e a sociedade que o produziu. O debate 
historiográfico sobre os sentidos sociais do audiovisual mostra que a análise de aspectos culturais indica que o cinema não se desenvolve de forma independente de forças tecnológicas, econômicas e ideológicas. Dessa forma, o cinema é altamente mediado, e os filmes baseados em temas históricos são importantes instrumentos para a rememoração coletiva e essa discussão reforça que a produção do filme traz a produção de ideologia; o filme pode ser também um instrumento de persuasão da ideologia dominante (VALIM, 2005). Em outras palavras, no contexto da sala de aula e de um cineclube essa persuasão pode estruturar-se como importante medida de aprendizagem histórica.

Se inicialmente o cinema foi usado como um instrumento das forças dominantes para repassar ideologias à sociedade, no Brasil durante o governo de Getúlio Vargas o audiovisual foi utilizado como um instrumento divulgador da cultura e unificador do Estado. Para alcançar esses objetivos foi criado o Instituto Nacional do Cinema Educativo (INCE). A perspectiva pedagógica, nas décadas de 1930 e 1940, não possuía preocupações teórico-metodológicas definidas, mas sim motivações ilustrativas, pois seu principal objetivo era utilizar o cinema como instrumento ideológico de massa para atender os interesses do Estado, dessa forma, segundo Nascimento (2008), o Brasil entrou em uma conjuntura internacional em que o Estado usava o cinema para fins políticos, como os países com regimes totalitários como a antiga URSS, Alemanha e Itália.

Ainda que seu uso como fonte tenha marcado o século $X X$, no tempo presente o cinema passou a ganhar espaço mais significativo nas discussões pedagógicas, assim como em livros e revistas científicas, surgindo artigos e livros que discutem com mais frequência o uso do cinema em sala de aula, assim como nas universidades surgem dissertações e teses de doutorado que abordam o uso do cinema nos mais diversos aspectos. Atualmente os estudos relacionados ao binômio cinema-história estão sendo muito discutidos, assim como tem sido criadas várias possibilidades de utilização do filme como método de ensino, porém nem todos os professores estão habituados a lidar com esse instrumento, permanecendo assim na maioria das vezes o método tradicional de aula expositiva e utilização do livro didático, assim como a maioria das escolas não tem estrutura para receber e utilizar o cinema como prática pedagógica. 
O fato das imagens cinematográficas terem sido por um longo tempo ignoradas pelos historiadores levou consequentemente à quase exclusão desse tópico nas universidades, o que corroborou com uso dessa ferramenta nas aulas de história sem qualquer fundamento metodológico (BITTENCOURT, 2008, p. 373). Pode-se notar que a utilização do cinema na sala de aula tem sido com frequência realizada pelos professores sem qualquer preparação, tornando o filme apenas um objeto de entretenimento para os alunos. Uma pesquisa realizada por Nascimento (2008) com professores aponta que:

\begin{abstract}
A maioria dos professores respondeu que não trabalha com filmes porque suas escolas não tem um espaço adequado para exibição, por não ter habilidade para manusear os aparelhos eletrônicos, e por não encontrar filmes didáticos nas locadoras, além do fato já apontado que tem dificuldade de trabalhar didaticamente filmes por não ter experiência (NASCIMENTO, 2008, p. 8).
\end{abstract}

Apesar da pesquisa de Nascimento ter sido realizada na Bahia, ela aponta para a uma realidade compartilhada pelas escolas da região norte, notadamente pelas escolas do interior do estado do Pará. Na região de Bragança as escolas muitas vezes não têm estrutura adequada para uso de filmes e os professores, em geral, não estão capacitados para utilização do mesmo no cotidiano escolar. Além disso, o curto período de tempo que as aulas de história têm na grade curricular, além da rotina corrida que a maioria dos professores possui acabam fazendo com que o uso dos filmes se torne pouco comum nas aulas. Considerando que em Bragança e na maioria das cidades da Amazônia não há salas de cinema, o audiovisual fruto do seu tempo, que repassa os valores, cultura, consciência social e histórica permanece como meio subutilizado pela educação pública.

Apesar de haver muitos obstáculos e circunstâncias que na prática quase inviabilizam o uso do cinema em muitas escolas, é preciso pensar alternativas para que o professor possa utilizar filmes na sala de aula. Como esse professor pode fazer o uso adequado do cinema em sala de aula? Há um modelo pronto e acabado que possa ser utilizado para ajudar na execução e análise do filme?

Atualmente muitas possibilidades existem para ajudar os professores a utilizar o filme de uma forma mais adequada, ou seja, que não envolva exclusivamente o entretenimento como objetivo principal. Algumas propostas metodológicas sobre o uso do cinema na sala de aula têm sido construídas por 
estudiosos da área, mas cabe ressaltar que não existe uma fórmula pronta, o que há são várias possibilidades metodológicas que contribuem na análise crítica do cinema.

Uma possibilidade levantada por Bittencourt (2008), é que para inserir os alunos nesse debate são necessários alguns passos importantes. O primeiro passo é que o professor deve conhecer as preferências do seu grupo de alunos e identificar as experiências históricas deles como espectadores. O acúmulo dessas vivências e a reflexão sobre as mesmas deverão ser propulsores para a compreensão da condição social dos estudantes com buscas à aprendizagem histórica (RÜSEN, 2010). Em seguida deve-se preparar o grupo de alunos para a leitura crítica de filmes, seguindo de um terceiro momento em que seria necessário levantar questões sobre o objeto que vai ser analisado, tais como: O que é um filme? Como é feito e produzido? Quem trabalha nele? Quanto custa fazer um filme? Por que a maioria dos filmes que vimos no Brasil são norte-americanos? E, por último, fazer a análise crítica do filme levando em conta a leitura interna do filme, considerando roteiro, personagens, acontecimentos principais, cenários, lugares e tempo (BITTENCOURT, 2008; NAPOLITANO, 2009).

Estes passos não vão necessariamente fazer com que a aula aconteça de forma satisfatória, mas são alguns aspectos que podem contribuir para a realização da análise crítica do filme, tornando-se um facilitador do processo de ensinoaprendizagem, o professor tem a função de conduzir o debate, e fazer com que a aula se torne interessante e produtiva. Nascimento (2008) demostra em seu trabalho outros momentos importantes que podem ajudar no bom desempenho da prática pedagógica do professor. Antes de qualquer outra coisa, o professor precisa fazer o levantamento antecipado do filme, levando em conta a faixa etária dos alunos e o conteúdo da unidade, e depois, é preciso tomar outros cuidados como apontado por ele:

[...] o professor deve tomar alguns cuidados preliminares, imprescindíveis para o bom desempenho de sua prática pedagógica. Dois cuidados são necessários: o cuidado técnico-operacional e o metodológico. O cuidado técnico-operacional consiste na precaução que o professor deve ter em verificar, com certa antecedência, se os equipamentos eletrônicos estão em perfeitas condições de ser usados, para que não ocorra nenhuma surpresa no dia da aula. A parte metodológica é o suporte que orienta o bom andamento da 
atividade pedagógica. No caso em apreço, resume-se em dois momentos: a preparação e a execução (NASCIMENTO, 2008, p. 13).

A proposta sugerida por Nascimento (2008) se divide em dois momentos, preparação e execução, a preparação segue passos indispensáveis que são: assistir previamente o filme que se pretende usar, observar os detalhes do filme prestando atenção nas cenas, observando os diálogos importantes. Tudo deve ser anotado. Em seguida deve-se fazer uma pesquisa sobre o diretor e o contexto em que o filme foi produzido. Após ver o filme, é preciso que o professor faça ainda o planejamento da aula, expondo os objetivos, ou seja, o que pretende alcançar com o filme, os temas para a discussão, os critérios metodológicos e avaliativos.

Após a realização dessas etapas, o segundo momento é o da execução, o professor deve expor o seu planejamento, apresentar a sinopse do filme, dar informações sobre o diretor e a produção do filme. Nos pontos para a discussão, deve pedir que os estudantes façam anotações segundo os objetivos do plano de trabalho. O professor não deve se ausentar da sala durante a exibição do filme, sua presença é fundamental para coordenar a aula. Logo após realizar a análise propriamente dita do filme, é o momento de comentar e criticar o filme, lembrando que o professor não precisa ser um especialista na compreensão dos mecanismos de linguagens cinematográficas, mas ter apenas algumas noções básicas para enriquecer sua metodologia. Uma orientação importante é pedir que os alunos prestem atenção nos detalhes dos ângulos, nos planos e enquadramentos, aqueles detalhes que o diretor fez questão de ressaltar. Assim como deve-se prestar atenção na justaposição da imagem, diálogos e música. As perguntas elaboradas para o plano de aula vão servir para guiar a discussão no momento da crítica do filme. Outro ponto importante é articular o filme ao contexto em que ele surgiu e associá-lo ao mundo que o produziu ou a alguma outra fonte como jornal, fotografia, música, etc. Isso pode contribuir satisfatoriamente para a construção do conhecimento histórico dos alunos, além de promover e instigar o debate na sala de aula, provocando no aluno a tendência a construir seu próprio ponto de vista (NASCIMENTO, 2008).

Como vimos, cada grupo escolar e realidade local vão impor suas condições de realização das atividades com o cinema. Todos esses passos debatidos pela bibliografia especializada são contribuições para se construir uma boa aula. 
Existem várias possibilidades que aproximam o professor e os alunos dessa realidade, dinamizar e conduzir uma boa discussão na sala de aula é um bom começo para deixar de utilizar apenas o ensino tradicional de aula expositiva e leitura do livro didático, aproximando os alunos da cultura histórica, permitindo que conheçam as sensações e sentimentos que o filme desperta.

\section{O Cineclube da Aldeia: Cinema e aprendizagem histórica}

As sessões do Cineclube da Aldeia são realizadas uma vez por mês, onde cada sessão possui uma temática específica a partir do levantamento prévio das principais opressões localizadas na sociedade bragantina. O cineclube conta com palestrantes convidados e alunos da UFPA que tenham relação com coletivos afinados com a temática de cada filme. As sessões acontecem no espaço da Sala de videoconferência, localizada no Bloco I do Campus Universitário de Bragança da UFPA, e conta com um público composto em sua maioria por discentes da Faculdade de História, mas também há participação de discentes de pedagogia, matemática, ciências naturais e ciência biológicas. Na metodologia implementada, os debates ocorrem logo após a projeção dos filmes começando com uma breve explanação dos convidados que conduzem os debates discutindo em que o filme contribui para o ensino de história e para a formação cidadã.

Atualmente o Projeto conta com uma equipe de um professor coordenador, uma bolsista e oito voluntários que trabalham na organização, nos ajustes de equipamentos e na divulgação das sessões, além de serem realizadas reuniões de avaliação e de discussão de textos teóricos sobre a relação Cinema-história. As sessões geralmente acontecem em uma quarta-feira, no período noturno com divulgação das sessões normalmente duas semanas antes da data marcada. A experiência do Cineclube da Aldeia tem sido importante em buscar a participação dos discentes de outras áreas do campus, buscando trabalhar temas transversais que envolvam a formação na licenciatura, além de aproximar os estudantes de questões e comportamentos que precisam ser combatidos no âmbito da convivência no campus. No segundo semestre de 2018 as temáticas e os filmes identificados para serem debatidos na execução do projeto foram os seguintes: 


Quadro 1 - Temáticas e filmes selecionados para as sessões de 2018
\begin{tabular}{|l|l|}
\hline Temática & Filme selecionado \\
\hline Transexualidade & $\begin{array}{l}\text { Meninos não Choram. EUA, 1999. } \\
\text { Dir. Kimberly Pierce. }\end{array}$ \\
\hline Racismo & $\begin{array}{l}\text { Doze anos de escravidão. EUA, } 2014 . \\
\text { Dir. Steven Mcqueen. }\end{array}$ \\
\hline Meio ambiente & $\begin{array}{l}\text { O pesadelo de Darwin. França/Bélgica/Áustria, } 2004 . \\
\text { Dir. Hubert Sauper. }\end{array}$ \\
\hline Ditadura militar & $\begin{array}{l}\text { O ano em que os meus pais saíram de férias. Brasil, } \\
2006 . \\
\text { Dir. Cao Hamburguer }\end{array}$ \\
\hline Gênero & $\begin{array}{l}\text { O Diário de uma babá. EUA, 2006. } \\
\text { Dir. Roberto Pulcini, Shari Springer Berman }\end{array}$ \\
\hline
\end{tabular}

Fonte: Elaborada pelos autores.

A primeira sessão do Cineclube da Aldeia neste ciclo teve como temática central a diversidade sexual e de gênero, sendo Meninos não choram, um filme produzido nos Estados Unidos da América em 1999, pelo cineasta Kimberly Pierce, a obra selecionada. O filme é baseado em uma história real, e conta a história de um jovem que nasceu com o corpo socialmente compreendido como feminino, porém, a mesma não se identificava como mulher, enxergando-se na condição masculina no que se refere à sua identidade de gênero. Em sua experiência histórica ele se vê tomado de medo pelo preconceito e violência que aquela sociedade tinham em relação à sua condição. Em seguida, o personagem vai para uma cidade chamada Falls City, onde conhece uma jovem e se apaixona, contudo, sofre uma série de violências verbal, física e sexual.

O filme contém alguns termos considerados datados, que não correspondem mais aos debates contemporâneos sobre identidade de gênero. Aqui observamos uma maneira de como pautar a postulação de Nóvoa de que todas as manifestações interferem na apresentação do "seu tempo", transmitindo um conjunto de representações culturais e históricas (NOVÓA, 2008). Dessa forma, o filme Meninos não choram traz à tona um debate muito atual, que é como a sociedade vê as pessoas que se auto identificam com o gênero oposto ao socialmente atribuído na ocasião do nascimento e as decorrentes formas de 
violências que as pessoas trans geralmente vivenciam no seu ciclo familiar e na sociedade em geral, assim como as formas de resistência utilizadas no cotidiano. O filme escolhido é, portanto, de bastante relevância para se discutir violência, abusos e também conquistas que a comunidade LGBT tem obtido, mas especificamente como a sociedade local compreende as pessoas trans. Uma questão decorrente da presente reflexão é pensar no que essas discussões contribuíram ou podem contribuir para a aprendizagem histórica.

Ao longo do debate notou-se que a maioria das pessoas presentes tinha diversas dúvidas de como se referir às pessoas trans e como discutir essa questão em sala de aula. Essas dúvidas foram acompanhadas de outras dificuldades sobre como agir com um aluno(a) que começa a se afirmar como um homem ou mulher trans. Foi pautado ainda como a comunidade LGBT em geral sobre preconceitos dentro da própria universidade, e a necessidade de combater, formar e conscientizar educadores que possam respeitar as diferenças e levá-las para sala de aula.

A segunda sessão do Cineclube da Aldeia apresentou o tema do racismo e teve como filme 12 anos de escravidão, uma película lançada em 2014 e ganhadora do Globo de Ouro de melhor filme. Dirigido por Steve McQueen. Baseado na vida de Solomom Northup, um negro livre que em 1841 vivia ao lado de sua esposa e filhos. No entanto, um dia após aceitar um trabalho que o levaria para fora da cidade, ele é sequestrado e acorrentado e acaba sendo vendido como escravo e a partir de então enfrenta uma série de violências e violações de direitos. Em seguida, ao longo de 12 anos ele passa por dois senhores que exploram seus serviços de várias maneiras.

Essa sessão teve bastante repercussão no Cineclube da Aldeia com o intuito de levantar o debate sobre o processo de escravidão e como a população negra encara até hoje as permanências de estereótipos. O debate gerado após a reprodução do filme não fugiu do planejamento, os palestrantes convidados levantaram um debate a partir de elementos visualizados no filme como a própria histórica da escravidão, debatendo a violência física e simbólica que os africanos escravizados sofriam. Em sintonia com o debate historiográfico contemporâneo sobre o tema foram observadas as várias formas de resistência (cantar, suicídio, tentativa de fuga), além de ressaltadas as questões de como a população negra é 
afetada pelos estereótipos construídos e como os comportamentos racistas estruturam-se até a história do tempo presente. O grupo presente concluiu que a universidade e as escolas não devem ficar isentas no combate às manifestações de opressão étnicas, especialmente no que se refere ao racismo institucional.

No contexto da discussão sobre a relação entre cinema e história, foi questionada por uma aluna do curso de história como o filme em questão serviria para uma prática de ensino libertadora. O filme 12 anos de escravidão, assim como outros filmes sobre representações do mundo escravista colonial podem ser utilizados para desconstruir estereótipos, para ressignificar a história da resistência da população negra e como se deu o processo de escravidão e buscas da liberdade por parte dos negros. Ficou evidente a necessidade de debater a mentalidade dos alunos de que todo negro era escravo até o fim do regime escravocrata, ideia que até mesmo os livros didáticos reforçam. O filme ajuda a discutir a temática especialmente por ser um mecanismo de linguagem e sensibilidades quanto às torturas e agressões, tornando o aluno mais próximo dessas experiências. Nesse ponto concordamos com Nóvoa quando diz que:

Em nenhuma outra forma de expressão algo que é imanente na comunicação entre os seres humanos, algo que é inerente à condição humana adquire tanta verossimilhança e fidedignidade. $\mathrm{O}$ cinema é uma forma de expressão onde a razão aparece mesclada a tudo mais que é humano como pensamento e como sentimento (NOVÓA, 2008, p. 6).

Com isso podemos perceber que um filme como 12 anos de escravidão constitui-se como um mecanismo de linguagem que possui uma grande capacidade de comunicação, especificamente por envolver pensamentos e sentimentos, quando estamos assistindo algo e aparecem cenas de dor, alegria ou raiva, e nos vemos tensionados a compartilhar do sentimento que está sendo expresso. Tal premissa adquire maior dramaticidade em busca da aprendizagem histórica proposta por Rüsen (2010), se pensarmos que os estudantes da rede pública de Bragança são em grande parte de origens familiares afroindígenas.

A sessão seguinte trabalhou o documentário "O pesadelo de Darwin", dirigido por Hubert Sauper, que estreou em 2004. O filme retrata a Tanzânia, quando foram soltos no Lago Vitória, em meados do século XX, exemplares da perca do Nilo, um peixe predador que em pouco tempo eliminou outras espécies que havia no lago. 
Desse novo peixe é possível obter um filé do grande pescado que passa a ser exportado para a Europa, onde são muito consumidos. Com isso uma cadeia exploradora que envolve pescadores, fábricas, pilotos de aviões e os grandes exportadores se estrutura na Tanzânia em meio à pobreza e à miséria que caracterizam a região.

O documentário mostra o grande comércio de exportação que esse pescado começou a movimentar e os problemas que são gerados a partir dessa atividade exploratória. Um deles é o impacto ambiental, devido à poluição do lago, ocorre a diminuição das espécies. No entanto, além disso, o filme reporta que junto com a exportação de filé, os aviões que chegavam na Tanzânia para levar o pescado para a Europa acabam levando armas para os países vizinhos que se encontravam em guerra civil. Além disso, a chegada dos pilotos alimentava uma rede de exploração sexual de mulheres deixando muitas delas sujeitas a diversos tipos de violência, além de estarem expostas às doenças sexualmente transmissíveis, especialmente a AIDS. A doença, aliás, firmava-se como grande problema de saúde pública na África ao lado da fome acompanhada do uso de drogas associado ao tráfico.

A temática representada no filme não está tão distante de algumas vivenciadas na própria Amazônia, onde a exploração dos recursos naturais e minerais da região é constante. Em Bragança e seu entorno, considerado Amazônia Atlântica, muitas empresas montam seus negócios com promessas de geração de empregos, apesar disso o que os alunos observaram é que os produtos explorados saem do seu local de origem para exportação alterando a dinâmica de preço dos produtos que ficam no local de origem, além de gerar outros problemas para a comunidade. A experiência histórica da África Oriental expressa no filme sinalizou que o documentário pode ser abordado de diversas formas, mas frisou-se a necessidade do professor utilizá-lo fazendo uma relação do que o filme aborda na Tanzânia com as questões regionais, aproximando os alunos da realidade que o cerca, tais como a violência, a prostituição, a pobreza, etc.

A quarta sessão do ciclo teve como filme projetado $O$ ano em que meus pais saíram de férias, lançado em 2006, dirigido por Cao Hamburger. O longametragem conta a história de Mauro, um menino de 12 anos que inicialmente vê seus pais "saírem de férias", mas que, na verdade, os mesmos foram obrigados a fugir por estarem sendo perseguidos pela ditadura militar deixando Mauro com o 
avô. O avô de Mauro acaba falecendo e ele fica na companhia de um vizinho, a partir de então, Mauro precisa lidar com sua nova realidade, enquanto espera por seus pais e acompanha a seleção brasileira na Copa do Mundo de 1970.

O filme foi bem recebido pelo público, pois retrata a história pela ótica de um menino que estava entusiasmado com o Campeonato Mundial de Futebol. No contexto da euforia do torneiro, o filme mostra como Mauro vive na expectativa do retorno de seus pais e como eles demoram a voltar, momento em que o menino começa a perceber que algo está errado. A Copa de 1970 aconteceu em um período em que a propaganda do regime defendia que o Brasil estava avançando, e o futebol surgia como um instrumento para apaziguar as tensões políticas, tirar de foco os acontecimentos que não deveriam vir à tona na sociedade, já que os anos 1970 foi o período de maior repressão da ditadura militar.

A sessão obteve maior participação dos ouvintes que as anteriores, onde ao explanaram sobre o tema vários estudantes falaram sobre a questão do futebol como emblema do nacionalismo. Foram lembradas ainda pessoas no universo do futebol que eram contrárias ao regime militar, assim como foram mencionadas as músicas do filme que traziam o discurso nacionalista da época. Muitos outros elementos foram mencionados, com a ambientação do filme no Bom Retiro, um bairro de São Paulo que abriga judeus, italianos e outras culturas, local onde Mauro foi morar e teve que se adaptar a novos costumes e modos de vida. Foi citado também no debate a importância da restauração da democracia depois de períodos de exceção. A participação da sociedade na política e o uso consciente do voto traduziram os anseios do grupo presente. Um dos destaques foi o fato do filme não ser uma representação comum sobre a ditadura militar ao optar por enfatizar o cotidiano, sem exibir cenas de torturas. Ou seja, $O$ ano em que os meus pais saíram de férias é um filme que pode ser usado na sala de aula com potencial para atrair o interesse dos alunos através do diálogo com o esporte.

A última sessão foi com o filme Diário de uma Babá, comédia romântica onde Anne Braddock uma jovem recém-saída da faculdade que vive em um bairro operário de Nova York, apesar de pressionada pela mãe para encontrar um lugar no mundo dos negócios, acaba aceitando um emprego de babá na casa de uma família rica de Manhattam. No universo desse trabalho é que a jovem enfrentará uma série de dilemas com seus patrões. 
O debate aconteceu principalmente no âmbito das relações de gênero e de como as mesmas são tecidas entre a babá e sua patroa e entre a patroa com o seu marido. Foram comentadas a divisão social entre esses personagens com análise de algumas cenas específicas. Pôde-se perceber a frequente naturalização de funções atribuídas às mulheres, como o papel de mãe e organizadora do lar, enquanto que, para os homens, cabe o papel de provedor da casa. As observações feitas evidenciaram as formas de transmissão de performances relativas ao gênero de geração para geração, além de enfatizarem que as relações de gênero são também enviesadas por relações étnicas e de classe social. O filme mostra a relação da esposa com o marido, da patroa com a babá, sendo importante ressaltar que apesar de toda violência simbólica vivenciada pela babá e por sua patroa, há de certa forma uma sororidade, que é a forma de entender a dor de outra mulher e colaborar com a mesma.

E meio a esse debate surgiram questionamentos sobre como se podem adequar essas questões para o cotidiano dos alunos, como falar sobre gênero para crianças. Concluiu-se que esse processo de aprendizagem se dá fazendo pequenas perguntas cotidianas, trabalhando a questão de gênero e a igualdade nas escolas de acordo com a faixa etária. Uma discente descreveu que a temática é muito importante para se entender mais sobre a desigualdade de gênero herdeira das estruturas patriarcais da sociedade brasileira. Um outro descreveu a necessidade de se debater temas como esse, pois nos dias atuais ainda se vê a naturalização da submissão da mulher em relação ao homem. A organização dos debates em ciclos, cadenciados na dinâmica do cineclubismo permite a associação e cruzamento de opressões específicas que outrora podiam ser percebidas apenas de maneira estanque.

Desde a sessão do filme $O$ ano em que os meus saíram de férias o projeto passou a circular entre a plateia uma ficha com o objetivo de avaliar a escolha do filme, o debate e a proposta do cineclube. Tal iniciativa foi uma ideia que surgiu após a realização de algumas sessões, acreditando que seria importante saber se a atividade estava sendo assimilada de maneira adequada, além de conhecer melhor o perfil de quem estava frequentando o projeto com espaço para sugestões e melhorias na dinâmica do cineclube, além de sabermos se a atividade estava alcançando alunos de outros cursos do campus, de outras instituições e da 
educação básica. As fichas foram utilizadas nas duas últimas sessões e observouse que mais da metade das respostas relataram que os temas abordados foram relevantes e proveitosos, além de mencionarem a importância da permanência das atividades do cineclube em uma cidade que não conta com nenhuma sala de cinema.

\section{Considerações Finais}

O cineclube foi uma atividade agregadora de vários cursos de licenciatura. Por meio das fichas utilizadas nas duas sessões últimas pôde-se notar a participação de discentes de vários cursos do Campus de Bragança, como Pedagogia, Letras Língua Portuguesa, Ciências Naturais, Biologia e Matemática, apesar da maior parte dos participantes serem do curso de História. As temáticas abordadas através da utilização dos filmes foram consideradas muito importantes, pois tratam das opressões vivenciadas por grupos historicamente marginalizado apresentando alguns temas absolutamente inéditos no cotidiano da formação dos alunos, como a questão da transexualidade, que é um assunto pouco abordado na escola e nas universidades.

Algumas dificuldades foram encontradas, notadamente a falta de equipamentos disponíveis para serem utilizados que era frequente, assim como as dificuldades em alcançar público em algumas sessões que abordaram temáticas consideradas mais específicas ou identitárias. Além disso, não foi possível alcançar um dos objetivos do projeto que era realizar sessões no espaço das escolas da rede pública existentes no município de Bragança em função de um contexto de carência de espaços, dificuldade de reunião com as coordenações acadêmicas e instabilidade de calendários de reposição de greves. Igualmente foi apenas eventual a presença de plateia do ensino médio nas dependências da universidade, tendo o projeto ficado mais restrito à perspectiva de capacitação de docentes em formação. A prática do cineclube confirmou que a aprendizagem histórica não se assegura no curto prazo, mas deve ser perseguida no cotidiano da formação docente.

\section{Referências}


AMÂNCIO, Thiago._Brasil registra 606 casos de violência doméstica e 164 estupros por dia. Folha de São Paulo, São Paulo, 9 ago. 2018. Disponível em: https://www1.folha.uol.com.br/cotidiano/2018/08/brasil-registra-606-casos-deviolencia-domestica-e-164-estupros-por-dia.shtml. Acesso em: 23 nov. 2018.

ATLAS DO DESENVOLVIMENTO HUMANO NO BRASIL. Bragança, PA: caracterização do território. 2018. Disponível em: http://www.atlasbrasil.org.br/2013/pt/perfil_m/braganca_pa. Acesso em: 23 nov. 2018.

BITTENCOURT, Circe Maria Fernandes. Ensino de história: fundamentos e métodos. São Paulo: Cortez, 2008.

CHALHOUB, Sidney. Cidade febril: cortiços e epidemias na corte imperial. São Paulo: Companhia de Letras, 1996.

FERRO, Marc. Cinema e história. Rio de Janeiro: Paz e Terra, 1992.

IBGE. Bragança. [Rio de Janeiro]: IBGE, (C)2017. Disponível em: https://cidades.ibge.gov.br/brasil/pa/braganca. Acesso em: 23 nov. 2018.

IPEA - INSTITUTO DE PESQUISA ECONÔMICA APLICADA; FBSP - FÓRUM BRASILEIRO DE SEGURANÇA PÚBLICA. Atlas da Violência 2018. Rio de Janeiro: Ipea, $2018 . \quad$ Disponível em: http://www.ipea.gov.br/portal/images/stories/PDFs/relatorio_institucional/18060 4_atlas_da_violencia_2018.pdf. Acesso em: 23 nov. 2018.

MOREIRA, Brena. Zona Bragantina ganhará unidade do Pro Paz Integrado. Segup, Belém, 2018. Notícias. Disponível em: http://www.segup.pa.gov.br/noticias/zonabragantina-ganhar\%C3\%A1-unidade-do-pro-paz-integrado. Acesso em: 23 nov. 2018.

MORETTIN, Eduardo Victorio. O cinema como fonte histórica na obra de Marc Ferro. História: Questões \& Debates, Curitiba, v. 38. n. 1. p. 11-42, 2003.

MOTT, Luiz; MICHELS, Eduardo; PAULINHO. Pessoas LGBT mortas no Brasil: relatório 2017. Salvador: Grupo Gay da Bahia, [2018]. Disponível em: https://grupogaydabahia.files.wordpress.com/2020/03/relatorio-2017.pdf.

Acesso em: 23 nov. 2018.

NAPOLITANO, Marcos. Como usar o cinema em sala de aula. 4. ed. São Paulo: Contexto, 2009.

NASCIMENTO, Jairo Carvalho. Cinema e ensino de história: realidade escolar, propostas e praticas na sala de aula. Fênix: Revista de História e Estudos Culturais, [S. I.], v. 5, n. 2, p. 1-23, jun. 2008.

NOVÓA, Jorge. A relação Cinema-história e a razão poética na reconstrução do paradigma histórico. O olho da História, n 10. abr 2008. 
RÜSEN, Jörn. A razão histórica: Teoria da história: os fundamentos da ciência histórica. Brasília: UnB, 2010.

SILVA. Dário Benedito Rodrigues Nonato da. Os donos de São Benedito: convenções e rebeldias na luta entre o catolicismo e devocional da cultura na Bragança, século XX. 2006. Dissertação (Mestrado) - Universidade Federal do Pará, Belém, 2006.

SOUTO, Luiza. Assassinatos de LGBT crescem 30\% entre 2016 e 2017, segundo relatório. O Globo, [Rio de Janeiro], 17 jan. 2018. Disponível em: https://oglobo.globo.com/sociedade/assassinatos-de-lgbt-crescem-30-entre2016-2017-segundo-relatorio-22295785. Acesso em: 23 nov. 2018.

UFPA - UNIVERSIDADE FEDERAL DO PARÁ. Campus Universitário de Bragança. Histórico. Bragança, PA: UFPA, 2018. Disponível em: https://www.campusbraganca.ufpa.br/index.php/historico. Acesso em: 23 nov. 2018.

VALIM, Alexandre Busko. Entre textos, mediações e contexto: anotações para uma possível história social do cinema. História social, Campinas, n. 11, p. 17-40, 2005.

Recebido em 13 de Fevereiro de 2019. Aprovado em 28 de Abril de 2020. 